\title{
Subjective and objective risk perceptions and the willingness to pay for agricultural insurance: evidence from an in-the-field choice experiment in rural China
}

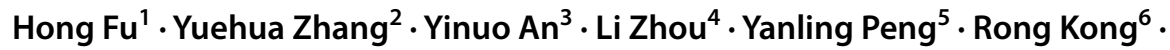 \\ Calum G. Turvey ${ }^{3}$ (D)
}

Received: 26 May 2020 / Accepted: 4 October 2021 / Published online: 19 October 2021 (c) International Association for the Study of Insurance Economics 2021

\begin{abstract}
We conducted in-the-field choice experiments in China to investigate farmers' willingness to pay for crop insurance and to determine how objective and subjective beliefs affect Willingness to Pay (WTP). We deploy three variants of the choice experiment using a priming mechanism on objective and subjective beliefs plus a control. We find that the cuing frame matters in that there are differences in WTP within five attributes and across variants. In terms of practical policy, our results suggest that farmers' frame of reference toward objective and subjective risks can affect insurance demand.
\end{abstract}

Keywords Agricultural insurance $\cdot$ Choice experiments $\cdot$ Subjective and objective risk $\cdot$ Risk perception $\cdot$ China

\section{Introduction}

China's expanding crop insurance industry in the modern era was initiated by the First Policy Document issued in 2004. Between 2007 and 2019, China has delivered agricultural indemnities of between 112.6 billion Chinese Renminbi (RMB) to 3.5 trillion RMB and agricultural insurance premiums have increased from 5.18 billion

Calum G. Turvey

cgt6@cornell.edu

1 Shandong University of Finance and Economics, Jinan, Shandong, China

2 Zhejiang University, Zhejiang, Zhejiang, China

3 Cornell University, Ithaca, NY, USA

4 Nanjing Agricultural University, Nanjing, Jiangsu, China

5 Sichuan Agricultural University, Chengdu, Sichuan, China

6 Northwest Agriculture and Forestry University, Yangling, Shaanxi, China 
RMB to 68 billion RMB. Presently, China provides public and private agricultural insurance services for over 178 million farmers covering 221 crops (China Banking and Insurance Regulatory Commission 2020). Despite this rapid growth in crop insurance offerings in China, relatively few studies have attempted to understand the risk motives affecting farmers' uptake and participation in the program.

How subjective and objective beliefs affect insurance decisions is an important economic problem and the subject of this paper. ${ }^{1}$ Turvey et al. (2013) investigated the relationship between objective and subjective beliefs and distributions applied to the crop insurance problem in China. Defining objective risks as those related to historical probabilities and subjective risks as those related to future probabilities they found that $82.3 \%$ of farmers perceived higher mean corn yields based on subjective risks than objective risks, while $71.63 \%$ revealed subjective corn yield standard deviations lower than objective standard deviations. They also found that beliefs farmers held with respect to subjective revenue risks strongly influenced the insurance participation decision, while beliefs about more positively skewed subjective distributions indicated a lower likelihood that farmers would purchase insurance. Turvey et al.'s (2013) results raise the prospect, and hypotheses, that (1) farmers are overconfident when it comes to subjective beliefs about future probabilities of crop yields, ${ }^{2}$ (2) farmers are more likely to rely on subjective than objective probabilities when it comes to making crop insurance decisions ${ }^{3}$; and (3) if insurers rely on objective (historical) distributions to write insurance contracts, while insureds rely on subjective distributions to determine the utility of those contracts, then behavioral frictions leading to market disequilibrium and non-participation can arise. ${ }^{4}$

\footnotetext{
1 Andersen et al. (2014, p. 208) define subjective probabilities as those probabilities that lead an agent to choose some prospects (e.g., insurance) over others (e.g., no insurance) when outcomes depend upon events that are not presently realized. Earlier interpretations by Knight (1921) define objective risk as unalterable, while subjective risks, or uncertainty, are alterable and malleable. Willett (1951) states that subjective uncertainty is a faithful interpretation of events in the external world. Pfeffer (1956) adds that risk is a combination of hazards measured by probability while uncertainty is measured by a degree of belief: Risk is a state of the world, but uncertainty is a state of the mind (c.f. Houston 1964).

2 Overconfidence can refer to an overestimation of one's ability or performance relative to others, selfimportance, or an excessive certainty about the accuracy of beliefs (Harrison and Swarthout 2019). While discrepancies in objective and subjective risk, and degrees of confidence, have been discussed in the agricultural economics literature, empirical works are very rare. Umarov and Sherrick (2005) test farmer overconfidence specifically and in the context of crop insurance. Overconfidence can result from miscalibration (Lichtenstein et al. 1982), optimism, and the 'better than average' effect (Svenson 1981; Gervais et al. 2002). Umarov and Sherrick (2005) find that farmers tend to be overconfident.

3 When subjective beliefs dominate objective beliefs Umarov and Sherrick (2005) argue that not only would the willingness to pay for insurance decline, but so too will be the imperative that insurance is required at all. They find that only 6-7\% of farmers admitted yields lower than the (detrended) county average, and only $15-15 \%$ reported a higher variability. Moreover, they find a mix of calibration curves which map (cross-tabulate) objective and subjective crop yield probability distributions. They found multiple over-underconfident typologies across mean, variance and skewness as was also found for Chinese farmers (Turvey et al. 2013). Buzby et al. (1994) investigated objective and subjective risks of Kentucky farmers and found an inclination to overestimate yield and underestimate risk.

4 Pease et al. (1993), Sherrick (2002) and Bessler (1980) make similar assertions, but in a direct test, Umarov and Sherrick (2005) found no relationship between miscalibration and insurance demand. Ramirez and Carpio (2012) similarly find a disconnect between the objective measures used to calculate crop
} 
Behavioral approaches to understanding insurance markets are not new. Kunreuther and Pauly (2018) note that laboratory experiments and field studies indicate that individuals often make insurance purchase decisions based on factors such as past experience and emotions. For example, individuals believing that there has been a decrease or increase in the probability of loss can decrease or increase insurance demand and/or coverage. Experiments in Kunreuther and Pauly (2018) show that loss experience and the emotion (or feeling) that it carries can impact whether an individual switches insurance status from uninsured to insured following a bad outcome or insured to uninsured following good outcomes in which no indemnity was received. On the other hand, insureds with good feeling or gratification switched insurance status much less. Johnson et al. (1993) find that framing can create biases in probability assessment and in perception of loss and these can affect insurance decisions. Similarly, studies by Hsee and Menon (1999) and Hsee and Kunreuther (2000) assert that the affect heuristic (Slovic et al. 2002) is an important determinant of insurance decisions. ${ }^{5}$ This suggest that the willingness to purchase and pay for insurance is not based on objective probability assessment as the Expected Utility Theory proposes, but rather on the degree by which the insurance consoles (consolation hypothesis) the insured. Fischhoff et al. (1978) find that the judgements of risk and benefits are negatively correlated. In the insurance context, the contract can be perceived as being high in benefits when a payoff occurs, but low in risk since the most that can be lost is the premium. On the other hand, if probability of loss is perceived as being low, the loss of premium is viewed as a high risk. If farmers exhibit systematic biases in how they judge insurance contracts markets may fail to operate efficiently. At least one study, by Babcock (2015) for crop insurance in the United States, provides experimental evidence of this effect.

While the literature on behavior and insurance is broad and draws from multiple disciplines including economics and psychology a common theme emerges: Perceptions of risk related to insurance can significantly affect insurance purchase decisions and the willingness to pay for insurance. ${ }^{6}$ This in turn has consequences

\footnotetext{
Footnote 4 (continued)

insurance premiums and how farmers judged those premiums. In the USA Gardner and Kramer (1986) and Glauber (2004) argue that farmers have required subsidies to encourage enrollment in crop insurance, and this may well be due to misaligned perceptions of objective and subjective risks. Similar results have been found in studies on the heterogeneity of risk by Spinnewijn (2012) outside of agriculture.

5 This approach has evolved into a science of risk perceptions by Fischhoff et al. (1977), Camerer and Lovallo (1999) and others.

${ }^{6}$ Drawing on Eckles and Wise (2013), Babcock (2015) uses a representative farmer model to examine revenue assurance in the USA using prospect theory (Kahneman and Tversky 1979; Tversky and Kahneman 1992). As with Eckles and Wise (2013), Babcock (2015) observed that many USA farmers do not buy the maximum amount of insurance available but will elect lower coverage levels. Under Prospect Theory farmers would place greater weight on economic losses than economic gains and would therefore, at least in theory, have greater demand for crop insurance and with higher coverage levels. Babcock (2015) does not find support for this model. Instead, he concludes that observed behavior for revenue protection insurance is more akin to an investment choice independent of underlying risks. More recently, Dalhaus et al. (2020) state that the cumulative prospect theory, applied to adjusted crop insurance according to farmers' preferences, is more consistent with farmers' willingness to pay. In this framework, high premiums without an offsetting indemnity is weighted as a loss which then diminishes demand.
} 
for the development and marketing of insurance products and policy generally, and more specifically developing agricultural insurance markets.

We explore how objective and subjective beliefs affect farmer's demand for crop insurance in China. We report in-the-field choice experiments (CE) applied to Chinese wheat farmers in Shaanxi and Shandong provinces. Although Chinese farmers are generally well diversified and multi-crop between wheat, corn, rice, vegetables and fruit, we focus on wheat because of its prominence in production along with corn and rice in the target areas. Our choice experiment had 3 randomly assigned variants differing only in the preamble read to the farmer. This is commonly referred to as priming. The 1st variant primed farmers to recall historical yields. The 2 nd variant primed farmers to consider the next crop grown (wheat). The 3rd variant was a control which did not prime farmers at all. The underlying theory relates to whether farmers primed to objective beliefs or, alternatively, subjective beliefs would respond differently to insurance attributes and willingness to pay (WTP) for these attributes.

\section{Methods}

\subsection{Choice experiment}

We use in-the-field choice experiments to derive willingness to pay (WTP) for attributes on agricultural insurance. Choice experiments provide a means to introduce exogenous variation into a revealed preference situation that may not arise at the individual level in practice. For example, a survey might indicate a level of insurance coverage for a given crop and the premium paid for the insurance, but in the short time horizon of a survey there will unlikely be enough variation to capture demand attribute effects. In the choice experiment, respondents make decisions in choice scenarios that involve a discrete number of alternatives. Each alternative is described by levels of a set of predefined attributes. The tradeoff between different crop insurance alternatives can therefore be analyzed through the choices that farmers make. Furthermore, if there is a price-related attribute in the experiment design, the willingness to pay (WTP) for other attributes can be estimated (McFadden 1973, 2001).

The experimental protocols including the choice experiment design and followon survey was reviewed by, and met the ethical standards and protocols of, Cornell University's Internal Review Board. To ensure compatibility between English and Chinese, the experiment and survey were first prepared in English by the graduate student in charge, then translated into Chinese by a second group of students, and back-translated from Chinese to English by a third group of students. Any wording differences were then remedied. Where appropriate Chinese colloquialisms were favored since these would be most common to farmers. 
In comparison to many experimental studies that use controlled laboratories settings, our study was necessarily conducted in-the-field at the farmers' location which was either at their residence or a village center easily accessible to respondents. Our study took place between October 15th and November 3rd 2019. ${ }^{7}$ This time frame conveniently fell between the harvesting of corn and the planting of wheat and at a time that many migrant laborers had returned home. Farmers were paid 30 Renminbi (RMB or Yuan, or about \$4.28 USD) in cash for participating in the experiment. We were aided locally by village leaders and/or local extension workers or agronomists from the Ministry of Agriculture. Transportation to rural villages was done by bus. Whether we attended a residence, or a local center depended upon local conditions. A survey team of mostly graduate students from host universities ${ }^{8}$ conducted the survey on a person-to-person basis. All students were trained prior to the experiment. Teams were always led by at least two graduate students from Cornell University with a Cornell professor and at least one local professor in attendance. At the end of each day students reviewed all survey forms to ensure clarity and legibility. In so doing, all data were cleaned and verified before being entered into a master database.

To determine sample size we used a protocol commonly used in choice experiments (Orme 1998; Johnson and Orme 2003; and Rose and Bliemer 2013) to calculate the minimum sample size:

$$
N \geq 500\left(\frac{l^{*}}{S \times J}\right)
$$

Here, $S$ is the number of choice tasks presented to each respondent ( 9 , in our case), $\mathrm{J}$ is the number of alternatives per choice task ( 3 in our case), and $l^{*} N$ is the largest number of levels of any of the attributes ( 5 for each choice). The rank condition is satisfied for $N=93$. Our original sample included 144 farmers each from Shaanxi and Shandong and 48 from Zhejiang. We dropped the Zhejiang sample because not enough farmers grew wheat, and for consistency only included wheat farmers from Shaanxi and Shandong. Our final sample was 241 farmers including 109 from Shaanxi and 132 from Shandong.

With the overall objective of determining whether objective or subjective beliefs can affect insurance demand and the WTP for certain insurance attributes we randomized among three variants by priming the farmer to consider the minimum, maximum and most likely yields from their historical recall (objective beliefs) or in relation to the next typical wheat harvest (subjective beliefs). The third variant, a control, used no priming at all. Figure 1 provides the three preambles used to prime the choice experiment. Our use of priming is well founded in the literature. For example, the affective primacy hypothesis (Zajonc 1980; Murphy and Zajonc

\footnotetext{
7 These predated the onset of COVID-19 which was first reported in Wuhan, Hubei Province in early December 2019.

8 These were Northwest Agricultural and Forestry University in Shaanxi Province, Nanjing Agricultural University in Jiangsu Province, Shandong University of Finance and Economics in Shandong Province, Zhejiang University in Zhejiang Province, and Sichuan Agricultural University in Sichuan Province.
} 


\begin{abstract}
Historical Priming for Objective Beliefs
If you have ever planted corn, rice or wheat, please refer to the historical highest, average, and lowest yield. Based on the historical average yield, presuming you were going to buy crop insurance for that period, choose one most favorable crop insurance option among 3 choices.

Future Priming for Subjective Beliefs

If you have ever planted corn, rice or wheat, please predict to the highest, most likely, and lowest yield for next planting season. Based on the prediction on the most likely yield, presuming you were going to buy crop insurance for next season, choose one most favorable crop insurance option among 3 choices.

\section{Control with no Priming}

Presuming you were going to buy crop insurance now, choose one most favorable crop insurance option among 3 choices.
\end{abstract}

Fig. 1 Priming for objective and subjective beliefs

1993) holds that positive and negative affective reactions can be evoked with minimal simulative inputs and virtually no cognition. The cognitive part deals with the rational assessment of probabilities presumed in expected utility. Affective reactions refer to feelings of goodness or badness, liking or disliking, pleasure or displeasure. If decisions of insurance choice involve affect then the pathway that steers choice is through observant and non-observant cues, and it is these cues that trigger affect (Zajonc 1980). Affect is prone to objective appeal. The crop was good or bad; or the crop will be good or bad. But in an experimental setting how the farmer feels about average crop yield or their distributions is unobservable to the researcher. By priming our choice experiment (CE) toward objective and subjective beliefs, we take a first step in this direction, and we find that priming matters. For example, we show later that farmers evaluating insurance with objective beliefs have different willingness to pay (WTP) for attributes than those primed to subjective beliefs and control. These are consistent with findings in Kusev et al. (2012) who find that accessibility of events in memory influences risk preferences. As a practical matter the policy implication of our paper is that farmers' decisions to participate in crop insurance programs may well be due to their frame of mind. See Fig. 1.

Our choice experiments are based on D-Optimal, 6-block design, with 9 cards per block and 3 choices per card. ${ }^{9}$ Farmers were presented with 9 cards, each of which had three choices of which the farmer was required to choose one. Each card had five attributes as listed in Table $1 .{ }^{10}$ Our attributes and terminology are based on terms used in Chinese crop insurance contracts and would be familiar to most farmers. Each attribute had between 2 and 5 levels which were varied for each card.

\footnotetext{
9 A D-Optimal design is an algorithmic approach to maximizing the determinant of the information set used in the design of experiments with multiple treatments. In our case, a fully orthogonal design across all attributes and levels as described in Table 1 would require all farmers to complete all possible combinations which would be $320(5 \times 4 \times 4 \times 2 \times 2)$ possibilities. A D-optimal design reduces the number of possibilities (in our case) to 6 blocks of 9 cards with 3 choices per card. It is non-orthogonal in that each farmer makes only 27 choices rather than 320 .

10 In Table $1 \mathrm{a} \mathrm{mu} \mathrm{(sometimes} \mathrm{spelled} \mathrm{mou)} \mathrm{is} \mathrm{a} \mathrm{unit} \mathrm{of} \mathrm{land} \mathrm{measurement} \mathrm{commonly} \mathrm{used} \mathrm{in} \mathrm{China.} 1$ $\mathrm{mu}=1 / 6$ th an acre or $1 / 15$ th a hectare.
} 
The 9 cards comprised a block. There were 6 blocks in the D-optimal design resulting in a total of 54 combinations of attributes and levels. Figure 2 provides images of the first 4 (of 9) cards in block 1 . The choice made by the farmer was recorded as a 1 , while the two alternatives not selected were recorded as 0 . These binary values were then used as the dependent values in the conditional and mixed Logit models described later.

The claim starting point is equivalent to coverage ratio as applied in the United States, and elsewhere, and captures the minimum damage ratio requirement of an insurance product so that farmers can get compensation. A claim starting point of $15 \%$ is equivalent to $85 \%$ coverage in the USA. We used 4 levels for crop insurance premiums. Insurance on grain is the most dominant insurance type in China, covering 70 percent of farmers. Premiums for grains (rice, wheat, and corn) ranged from $15 \mathrm{RMB} / \mathrm{mu}$ to $36 \mathrm{RMB} / \mathrm{mu}$ but are heavily subsidized. The subsidized premiums ranged from $3 \mathrm{RMB} / \mathrm{mu}$ to $7.2 \mathrm{RMB} / \mathrm{mu}$ (Anhui Agricultural Insurance 2019a, b). Our range from $1 \mathrm{RMB} / \mathrm{mu}$ to $15 \mathrm{RMB} / \mathrm{mu}$ includes an even greater subsidy at the lower end, and zero subsidy at the higher end (Anhui Agricultural Insurance 2019a). Indemnities are based on public crop insurance contracts (Anhui Agricultural Insurance $2019 \mathrm{~b}$ ) as the reference. The indemnity of wheat and rice is considered to be 240 to $600 \mathrm{RMB} / \mathrm{mu}$, and the indemnity of corn is around $350 \mathrm{RMB} / \mathrm{mu}$. As a result, we distributed the indemnity level from 300 to $600 \mathrm{RMB} / \mathrm{mu}$.

We also include a provider attribute. Chinese agricultural insurance market currently provides farmers with two major providers of agricultural insurance, which is our fourth attribute. One as government-owned agricultural insurance, the other as private-owned agricultural insurance, also called commercial agricultural insurance. Government-owned agricultural insurance is usually a government-led or government-established agricultural insurance company. Government-owned agricultural insurance takes into account the benefits of the whole society and provides farmers with different levels of subsidies on premiums. Government-owned agricultural insurance, however, lacks flexibility by providing a single rate for a single coverage level and indemnity structure. Commercial agricultural insurance on the other hand are fully market-oriented operations with the goal of maximizing profits. Farmers can choose the premium within the scope of insurable benefits, and even the indemnity can be negotiated. Nonetheless, Chinese farmers are suspicious of private insurers in terms of trust and contract performance, and therefore might have a preference for publicly provided insurance (Wang et al. 2020). For experimental work by Harrison and $\mathrm{Ng}$ (2018) has shown (in a different context) that failure of insurance companies to pay indemnities can impact insurance demand. Wang et al. (2020) in a series of choice experiments in China show that farmers' past experiences with insurance providers has a strong influence on their WTP for crop insurance.

The fifth attribute is whether the insurance can be used as loan collateral. This is a fresh but well-generalized concept of agricultural insurance in China. The Chinese government has initiated a new loan collateral option that links, or bundles, credit to agricultural insurance. ${ }^{11}$ In 2010, the China Banking and Insurance Regulatory

\footnotetext{
11 For a review of studies related to bundled credit see Ndegwa et al. (2020). Shee et al. (2021) report results of a choice experiment to evaluate attributes for insurance-bundled credit in Kenya.
} 


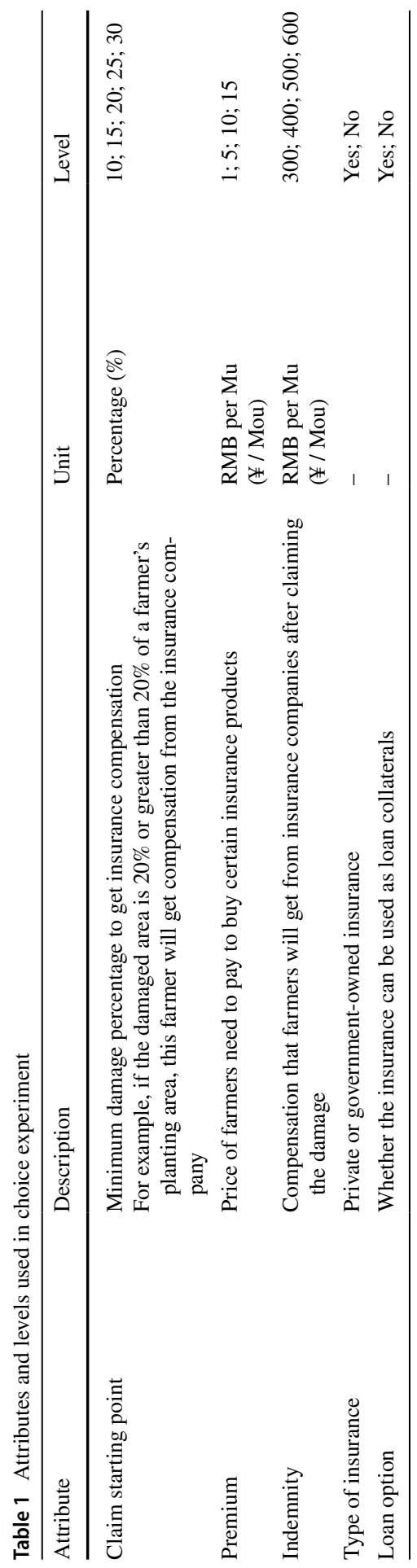




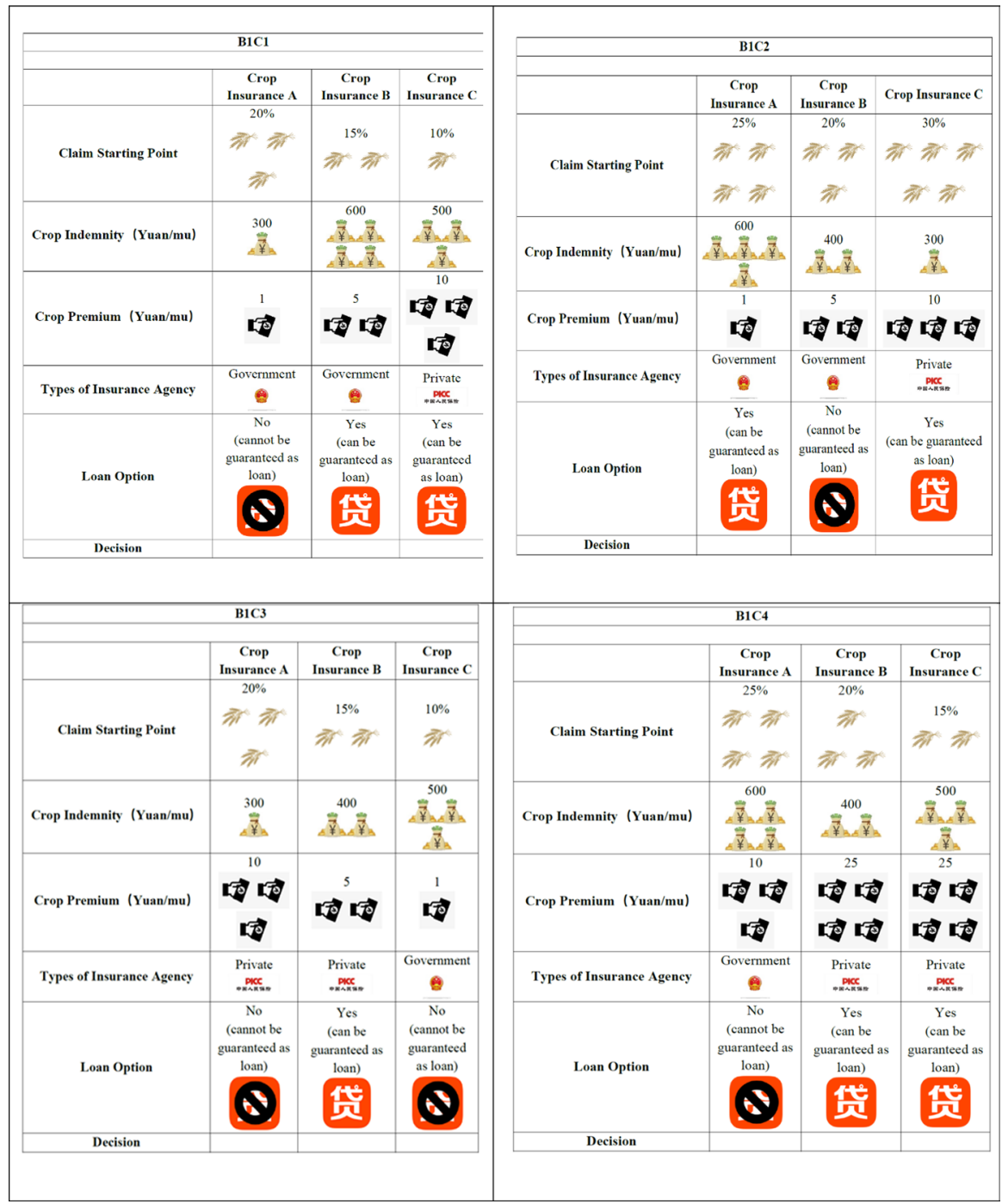

Fig. 2 Choice cards in block design

Commission (2010) released an official document named Opinions on Strengthening the Cooperation between Agriculture-related Credit and Agriculture-related Insurance. The document encouraged the cooperation between banks and agricultural insurance companies with favorable loan rates and faster loan application to farmers with agricultural insurance. In other words, this agricultural insurance contract could be used as loan collateral.

We presented the choices under the block design using cards with images and descriptions to make the attributes easier to understand. The four image in Fig. 2 represents the first 4 cards of the 9 card sequence in block \#1. These are identified 
as $\mathrm{B} 1 \mathrm{C} 1$ to $\mathrm{B} 1 \mathrm{C} 4$ on the cards. Cards were always presented in order from card 1 to card 9. Each farmer was randomly assigned to 1 of the 6 blocks. The nonorthogonal block design and reporting schedule was computed using JMP software. Each of the 3 variants (objective beliefs, subjective beliefs, control) used identical block designs, except the preamble/priming read to each respondent differed.

\subsection{Conditional Logit and mixed Logit models}

We apply both Conditional and Mixed Logit models using the choice selections indicated by the farmer's choice on each of the 9 cards $(=1)$ and those not selected $(=0)$. The conditional Logit model assumes that farmers have homogeneous preferences (i.e., WTP measures are the same for all farmers), while the mixed Logit model assumes that farmers have heterogeneous preferences (i.e., WTP measures are mixed across respondents). With each farmer responding to 9 cards the total sample for 241 farmers is $N=2169$. As ours is a conventional application of these models we refer the reader to McFadden (1973), Train (2009), McFadden et al. (1977) for greater econometric details. The willingness to pay can also be calculated by the Conditional Logit and the Mixed Logit model (Train 2009), which offers a more direct observation on sample preferences on various attributes over our choice experiment.

The conditional Logit model assumes that when each farmer respondent $(i)$ faces $j$ alternatives, the utility $U_{i j}$ that individual obtains from alternative $j$ can be decomposed into 2 parts: an indirect utility part $V_{i j}$ which is known by the researcher if alternative-specific attributes $X_{i j}^{\prime}$ and estimated preference parameters $\beta$ are known; and an unknown part $\varepsilon_{i j}$ that is treated as random error. With 6 blocks and 9 choice cards per block there are 54 choice sets (i.e., $J=54$ ) in our experiment. Each of these define a grouping which defines the conditioning factor of the conditional Logit model. The latent utility function is expressed as follows:

$$
U_{i j}=V_{i j}+\varepsilon_{i j}=X_{i j}^{\prime} \beta+\varepsilon_{i j}
$$

The conditional Logit model is obtained by assuming the random error $\varepsilon_{i j}$ is independently, identically distributed and follows type I extreme value distribution. Because individuals are assumed to be random utility maximizers, individual $i$ would choose alternative $j$ if and only if $U_{i j}>U_{i l}, \forall l \neq j$. Following McFadden (1973), the probability that individual $i$ chooses alternative $j$ has a closed form expression ${ }^{12}$ :

\footnotetext{
12 The Logit choice probability can be derived by solving: $P_{i j}=\operatorname{Pr}\left(V_{i j}+\varepsilon_{i j}>V_{i l}+\varepsilon_{i l}, \forall l \neq j\right)=$ $\operatorname{Pr}\left(\varepsilon_{i l}<\varepsilon_{i j}+V_{i j}-V_{i l}, \forall l \neq j\right)=\int\left(P_{i j} \mid \varepsilon_{i j}\right) \cdot f\left(\varepsilon_{i j}\right) d \varepsilon_{i j}=\int\left(\prod_{l \neq j} e^{-e^{-\left(\varepsilon_{i j}+V_{i j}-V_{i l i}\right)}}\right) e^{-\varepsilon_{i j}} e^{-e^{-\varepsilon_{i j}}} d \varepsilon_{i j}$, where the density function $f\left(\varepsilon_{i j}\right)=e^{-\varepsilon_{i j}} e^{-e^{-\varepsilon_{i j}}}$ and $P_{i j} \mid \varepsilon_{i j}=\prod_{l \neq j} F\left(\varepsilon_{i l}\right)=\prod_{l \neq j} e^{-e^{-\left(\varepsilon_{i j}+V_{i j}-V_{i l}\right)}}$ come from type I extreme value distribution.
} 


$$
P_{i j}=\frac{\exp \left(X_{i j}^{\prime} \beta\right)}{\sum_{l=1}^{l=J} \exp \left(X_{i l}^{\prime} \beta\right)}
$$

Specifically, in our choice experiment, the latent utility for individual $i$ to choose insurance bundle $j(j=1,2,3)$ is:

$$
U_{i j}=\beta_{1} C L A I M_{i j}+\beta_{2} P_{R E M I U M} i j+\beta_{3} I_{N D E M N I T Y}+\beta_{4} T Y P E_{i j}+\beta_{5} L O A N_{i j}+\varepsilon_{i j}
$$

The Logit probability for individual $i$ to choose loan $j(j=1,2,3)$ is

$$
P_{i j}=\frac{\exp \left(\beta_{1} \operatorname{CLAIM}_{i j}+\beta_{2} \text { PREMIUM }_{i j}+\beta_{3} \text { INDEMNITY }_{i j}+\beta_{4} \text { TYPE }_{i j}+\beta_{5} \operatorname{LOAN}_{i j}\right)}{\sum_{l=1}^{=I} \exp \left(\beta_{1} \text { CLAIM }_{i j}+\beta_{2} \text { PREMIUM }_{i j}+\beta_{3} \text { INDEMNITY }_{i j}+\beta_{4} \text { TYPE }_{i j}+\beta_{5} \operatorname{LOAN}_{i j}\right)}
$$

Additionally, because the utility value and Logit probabilities are unobservable, what we observe are the choice indicators $y_{i}=j(j=1,2,3)$, if $U_{i j}>U_{i l}, \forall l \neq j$. For a 3 -alternative design we generate 3 binary choice indicators:

$$
y_{i j}=\left\{\begin{array}{l}
1, U_{i j}>U_{i l}, \forall l \neq j \\
0, \text { if not }
\end{array}\right.
$$

The conditional Logit model is developed about alternative-specific attributes not individual-specific attributes. Alternatively, the mixed Logit model in our study is used to capture preference heterogeneity. Mixed Logit is a highly flexible model that can approximate any random model (McFadden and Train, 2000). It obviates the three limitations of conditional Logit by allowing for random taste variation, unrestricted substitution patterns, and correction in unobserved factors over time (Train, 2009). Consequently the mixed Logit model does not impose the independence of irrelevant alternatives axiom. ${ }^{13}$ The mixed Logit model is very similar to conditional Logit model in that its latent utility function can also be decomposed into 2 parts: one observable portion and one unobserved portion. As random utility the error component can be represented as comprising its mean, $\bar{\beta}$, and a deviation about that mean that varies across individuals, $\xi_{i}$. The only difference is that the observed portion of utility $V_{i j}$ now depends on a vector of individual-specific coefficients $\beta_{i}$.

\footnotetext{
13 One of the key differences between conditional (CL) and mixed Logit (ML) models is in the treatment of the independence of irrelevant alternatives (IIA) axiom. The axiom holds that for any set of alternatives, say $\mathrm{S}=\{\mathrm{A}, \mathrm{B}, \mathrm{C}\}$ and each with a selection probability $P_{A} P_{B}, P_{C}$, then the ratio of any two probabilities is independent of all other ratios of probabilities. In other words, the ratio $\frac{P_{A}}{P_{B}}$ will remain constant regardless of whether the respondent is presented with the set $S=\{A, B, C\}$ or $S^{\prime}=\{A, B\}$. Alternatively, the mixed Logit model treats each individual as part of a heterogeneous mix (random utility maximization). In this instance parameter estimates are comprised of the mean parameters of Logit estimates across choice sets or individuals and corresponding standard deviations. Because of this, error component utility can be correlated across individuals, thereby relaxing the IIA axiom. If the error component is small, or zero, the conditional and mixed Logit models provide similar results suggesting then that the IIA axiom holds. However, if parameter estimates are materially (and statistically) different between CL and ML this would indicate the presence of correlations among variables, that the ratios $\frac{P_{A}}{P_{B}}, \frac{P_{A}}{P_{B}}$ and $\frac{P_{A}}{P_{B}}$ are not independent, and the IIA axiom does not hold. In this case, the mixed Logit model has greater efficiency. For completeness we report both CL and ML results.
} 


$$
\begin{aligned}
U_{i j} & =V_{i j}+\varepsilon_{i j}=X_{i j}^{\prime} \bar{\beta}+X_{i j}^{\prime} \xi_{i}+\varepsilon_{i j} \\
& =X_{i j}^{\prime}\left(\bar{\beta}+\xi_{i}\right)+\varepsilon_{i j} \\
& =X_{i j}^{\prime} \beta_{i}+\varepsilon_{i j}
\end{aligned}
$$

Here, $\varepsilon_{i j}$ is still assumed to be distributed IID. In the conditional Logit model $E\left[X_{i j}^{\prime} \xi_{i}\right]=0$. However, in the mixed Logit model $\xi_{i}$ are allowed to be correlated across alternatives so that $E\left[X_{i j}^{\prime} \xi_{i}\right] \neq 0$ and the IIA assumption is relaxed. Thus, the conditional probability of respondent $i$ choosing alternative $j$ on knowing $\beta_{i}$ is given by

$$
P_{i j \mid \beta_{i}}=\frac{\exp \left(X_{i j}^{\prime}\left(\bar{\beta}+\xi_{i}\right)\right)}{\sum_{l=1}^{l=J} \exp \left(X_{i j}^{\prime}\left(\bar{\beta}+\xi_{i}\right)\right)}
$$

Like the conditional Logit model responses were grouped according to the choice set defined by the block design. These groupings are run as individual Logits with group coefficients aggregated to the mean, with standard deviations usually reported. Significance of the standard deviations implies that heterogeneity in attribute preferences across respondent farmers. Unlike conditional Logit, expression (7) cannot be solved analytically, and was therefore approximated using simulation methods (Train, 2009) in STATA.

\subsection{Willingness to pay (WTP)}

To better interpret the regression results of conditional and mixed Logit model, we use the estimated parameters to calculate respondents' willingness to pay (WTP). WTP measures how much the individual is willing to pay for a marginal increase in a given attractive attribute to keep total utility unchanged. It is equal to the marginal substitution rate between the given attribute and price attribute. In our model, we treat the insurance premium as the price attribute, and the WTP for the $k^{\text {th }}$ attribute as follows:

$$
W T P_{k}=-\frac{\partial U_{i j} / \partial X_{i j k}}{\partial U_{i j} / \partial P R E M I U M_{i j}}=-\frac{\widehat{\beta_{k}}}{\hat{\beta}_{2}}, k=1, \ldots, 5
$$

where $\hat{\beta}_{k}$ is the $k^{\text {th }}$ attribute estimator, and $\hat{\beta}_{2}$ is the estimator for insurance premium.

\section{Results}

\subsection{Socio-demographic characteristics in the sample}

Farmer demographics are summarized in Table 2. Most farmers interviewed were over 50 with a household size rounded to 5 . Land use rights held by farm households were 
Table 2 Some demographic characteristics of farmer respondents

\begin{tabular}{|c|c|c|c|c|c|c|c|c|}
\hline \multirow[t]{2}{*}{ Variable } & \multicolumn{2}{|c|}{$\begin{array}{l}\text { Objective } \\
(N=69)\end{array}$} & \multicolumn{2}{|c|}{$\begin{array}{l}\text { Subjective } \\
(N=85)\end{array}$} & \multicolumn{2}{|l|}{$\begin{array}{l}\text { Control } \\
(N=87)\end{array}$} & \multicolumn{2}{|c|}{ Total $(N=241)$} \\
\hline & Mean & SD & Mean & SD & Mean & SD & Mean & SD \\
\hline Gender & 0.55 & 0.5 & 0.41 & 0.5 & 0.39 & 0.49 & 0.44 & 0.5 \\
\hline Age & 56.86 & 12.22 & 54.15 & 12.83 & 55.69 & 10.78 & 55.48 & 11.95 \\
\hline Household size (number) & 4.48 & 1.97 & 4.8 & 1.53 & 4.82 & 1.63 & 4.71 & 1.7 \\
\hline Agricultural labor (number) & 2.33 & 1.15 & 2.19 & 1.1 & 1.98 & 0.83 & 2.15 & 1.03 \\
\hline Day labor (number) & 1.22 & 1.06 & 1.33 & 1.08 & 1.56 & 0.92 & 1.38 & 1.03 \\
\hline Household leader (yes/no) & 0.75 & 0.43 & 0.56 & 0.52 & 0.62 & 0.55 & 0.64 & 0.51 \\
\hline Education level* & 2.57 & 0.99 & 2.36 & 1.12 & 2.28 & 1 & 2.39 & 1.04 \\
\hline Farming years & 35.43 & 14.75 & 33.29 & 15.53 & 33.86 & 13.21 & 34.11 & 14.47 \\
\hline Lands owned $(\mathrm{Mu})$ & 9.47 & 6.68 & 7.58 & 8.43 & 6.23 & 3.8 & 7.63 & 6.66 \\
\hline Agricultural income (Yuan) & 16,314 & 17,159 & 8730 & 10,548 & 7638 & 11,768 & 10,507 & 13,630 \\
\hline $\begin{array}{l}\text { Non-agricultural income } \\
\text { (Yuan) }\end{array}$ & 30,772 & 33,221 & 29,993 & 31,9823 & 46,399 & 30,753 & 36,1615 & 32,699 \\
\hline Net profit (Yuan) & 13,831 & 40,390 & 16,224 & 31,580 & 27,639 & 27,183 & 19,627 & 33,401 \\
\hline
\end{tabular}

$* 0=$ Never Went to School, $1=$ At least elementary school, $2=$ At least middle school, $3=$ At least high school, $4=$ Some University or college, $5=$ Completed College or University

approximately $7.63 \mathrm{Mu}$ (1.27 acres) and experience in farming was approximately 34 years. Farmers we interviewed were approximately $44 \%$ men and $56 \%$ women. This is not atypical in China where many males are involved in wage labor locally or as migrant laborers. On average about 2.15 family members were involved in agriculture, while 1.03 worked for day wages off-farm. Educational levels were low with the highest academic achievement being between middle school and high school, and the household leaders were evenly distributed as well. The average education level for farmers is between middle school and high school. Average income from farm and nonfarm sources was 19,627 RMB/year or about \$2761 USD. Personal characteristics are similar between objective and subjective groups except for agricultural income. Agricultural income for farmers under objective group is higher than subjective and control group, but overall net profit is similar. As variants were randomized across participants, this outcome is purely by chance.

\subsection{Conditional and mixed Logit results}

The most significant finding, and we believe the main contribution of this paper, is that when primed to think only of historical risk, subjective risk, or no risk we find substantial differences across variants. The base conditional and mixed Logit results for objective, subjective and control groups are provided in Tables 3 and 4. Overall, we find strong consistency between the conditional and mixed Logit models. Wang et al. (2020) found considerable heterogeneity in their choice experiments in Northern China as we do here. The differences in parameter estimates we observe in our 
Table 3 Conditional Logit results

\begin{tabular}{lllll}
\hline Conditional Logit & Objective & Subjective & Control & Total \\
\hline Claim starting point & $-2.993^{* * *}$ & $-1.524^{* *}$ & $-1.263^{* *}$ & $-1.836^{* * *}$ \\
Crop premium & $-0.0500^{* * *}$ & $-0.0275^{* * *}$ & $-0.0406^{* * *}$ & $-0.0383^{* * *}$ \\
Crop indemnity & $0.00285^{* * *}$ & $0.00355^{* * *}$ & $0.00277^{* * *}$ & $0.00305^{* * *}$ \\
Types of insurance & $0.639^{* * *}$ & $0.701^{* * *}$ & $0.553^{* * *}$ & $0.626^{* * *}$ \\
Loan option & 0.0395 & $0.334^{* * *}$ & -0.0105 & $0.122^{* *}$ \\
Observations & 1863 & 2295 & 2349 & 6507 \\
\hline
\end{tabular}

Levels of significance indicated by $* * * \mathrm{p}<0.01,{ }^{* *} \mathrm{p}<0.05,{ }^{*} \mathrm{p}<0.1$

two models, while not exact across the three variants, are not so great that we can conclude the models provide different conclusions related to the demand for crop insurance in China. In other words, while we find significant disparities between variants, when each is compared between the conditional and mixed Logit models, the variants' coefficients are quite consistent. This suggests that while respondents have distinctive demand curves across variants, there is not a great disparity in the agricultural insurance demand curves within each variant.

Our main purpose, besides testing which attribute is the most important, is to test (as hypothesized) whether objective belief and subjective belief have a different impact on farmers' preference on crop insurance. Comparing variants based on objective and subjective risk, farmers in the subjective risk group tend to be less sensitive on claim starting point and premium, but more sensitive on indemnity than farmers in the objective risk group. Farmers in the subjective group are more likely to choose insurance than farmers under objective risk even if the claim starting point and insurance premium went up because they are considering that they will not need the crop insurance product next year since they tend to believe there is no serious yield damage in the future they predicted. For one unit in increased crop indemnity, because of their optimistic perception on yield, farmers in a subjective risk group will have higher willingness to purchase the insurance products compared to respondents in the objective group, meaning that they are focused mainly on the payout rather than the price and criteria of a certain crop insurance product.

For conditional Logit results (Table 3), higher claim starting point is more valuable for the objective group (with regression coefficient $\beta=-2.993$ ) than the subjective group $(\beta=-1.524)$ and the control $(\beta=-1.263)$. We had thought that if the subjective group was overconfident then they would have less of a preference for higher coverage than the control group. Using an approach similar to Turvey et al. (2013) we find that only $44 \%$ of farmers are overconfident, and $56 \%$ are underconfident. ${ }^{14}$ We find the objective group more sensitive to insurance

\footnotetext{
${ }^{14}$ More specifically, in a follow-on survey we queried farmers on the worst, most likely, and best yields they expect from the next wheat crop and then asked them to report the worst, typical, and best yields they recall from history. These were then used to generate crop yield distributions using the 3-parameter PERT distribution. The future yield estimates form the subjective probability distribution, while historical recall formed the objective yield distribution. Overconfidence is measured by the ratio of the means of the subjective to objective wheat yield distributions. Our measure of lower overconfidence than reported in Turvey et al. (2013) is likely due to recency effects and different locations.
} 


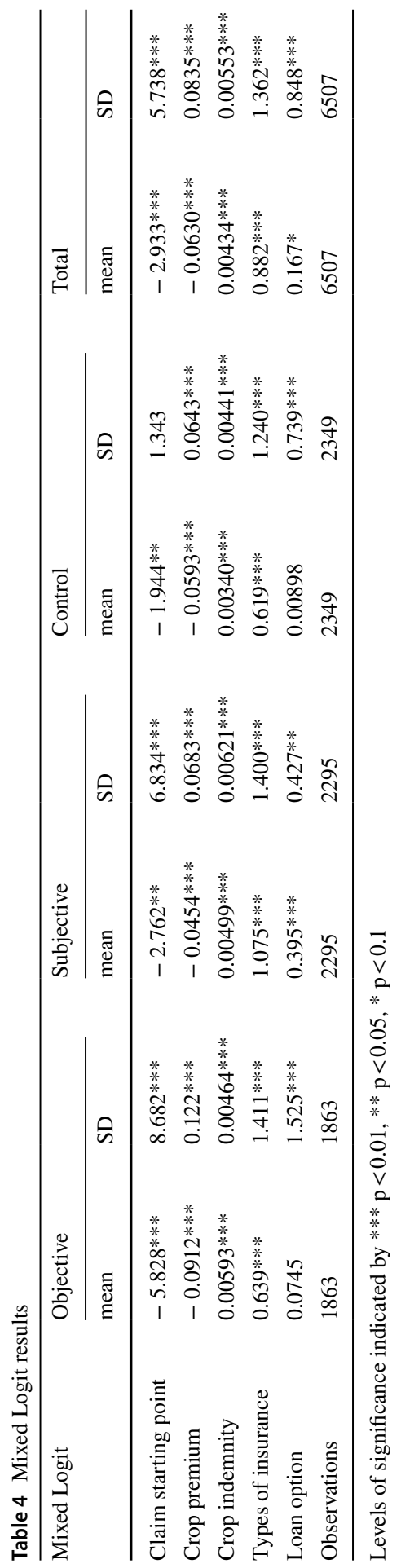


premiums $(\beta=-0.05)$ than the control group $(\beta=-0.0406)$ and the subjective group $(\beta=-0.0406)$. These results confirm a downward sloping demand curve with the greater disutility from higher premiums being the objective group. We find that utility increases with the loss indemnity and this is greater for the subjective grouping $(\beta=0.0036)$ than the objective group $(\beta=0.0029)$ and control $(\beta=0.0028)$. All three variants show a preference for government run vs privately run insurance, with the objective group having greater preference $(\beta=0.701)$ than the objective group $(\beta=0.639)$ or control $(\beta=0.553)$. We anticipated that these would be positive. Finally, we find mixed results for linked credit. Only the subjective group had a significant coefficient $(\beta=0.334)$ and this is difficult to explain. One possibility is that with an almost equal proportion of farmers being overconfident as underconfident at least some farmers may engage in risk-balancing, that is with a decrease in business risk from insurance, they are willing to take on greater financial risk. Evidence of risk-balancing along these lines has been documented in Turvey and Kong (2009) and Babcock (2015).

\subsection{Odds ratio}

Another approach to interpreting these results is by examining the odds ratio. From the utility specification of the Logit model, we can interpret utility $U_{i j}=L N\left(\frac{P_{i j}}{1-P_{i j}}\right)$ as the log of the odds ratio of selecting $\left(P_{i j}\right)$, or not selecting $\left(1-P_{i j}\right)$, a set of attributes. Then, marginal utility with respect to any particular attribute is given by $\frac{\partial U_{i j}}{\partial x_{j}}=e^{\beta_{j}}$. In other words, the marginal utility from changes in any of the attributes is given by the percentage change in the odds that the attribute will be favored, all other things held constant. The Logit coefficients represent increases or decreases in utility depending on the attribute. One unit increase in the attribute would add $\beta_{j}$ to respondents' utility, making them $e^{\beta_{j}}$ times more likely to insure. If $\beta_{j}<0$ then the odds is interpreted as decreasing the likelihood of insuring by $-\left(1-e^{\beta_{j}}\right) \%$ if the attribute increases by 1 unit. The odds ratios derived from Tables 3 and 4 are provided in Table 5.

The results show that the odds ratios are of similar scale between the conditional and mixed Logit models, but differ across the Objective, Subjective and Control variants. The aggregated Total effects are provided in the last columns. Insurance coverage, measured by the claim starting point shows a strong negative effect. Across all variants a decrease in insurance coverage decreases the odds of insuring by $84.1 \%$ in conditional Logit and $94.7 \%$ in mixed Logit. The odds are larger for farmers primed to consider historic/objective risks $(-0.950,-0.997)$ in comparison to forward/subjective risks $(-0.782,-0.937)$ with the lowest impact being the control $(-0.717,-0.857)$. Interestingly the odds ratios for insurance premiums are negligeable, which is likely because the insurance is heavily subsidized in practice. Nevertheless, the result suggests that the demand for insurance is quite inelastic with respect to price. On the other hand, the odds ratios for crop indemnity, types of insurance and loan option are viewed more favorably. An increase in the scale of indemnities has odds ranging from 1.003 to 1.006 , meaning that an increase will 
Table 5 Odds ratios for conditional (CL) and mixed (ML) Logit models

\begin{tabular}{lrrrrrrrrr}
\hline & \multicolumn{1}{l}{ Objective } & \multicolumn{3}{c}{ Subjective } & \multicolumn{2}{c}{ Control } & \multicolumn{2}{c}{ Total } \\
& CL & ML & CL & ML & CL & ML & CL & ML \\
\hline Claim starting point & -0.950 & -0.997 & -0.782 & -0.937 & -0.717 & -0.857 & -0.841 & -0.947 \\
Crop premium & -0.049 & -0.087 & -0.027 & -0.044 & -0.040 & -0.058 & -0.038 & -0.061 \\
Crop indemnity & 1.003 & 1.006 & 1.004 & 1.005 & 1.003 & 1.003 & 1.003 & 1.004 \\
Types of insurance & 1.895 & 1.895 & 2.016 & 2.930 & 1.738 & 1.857 & 1.870 & 2.416 \\
Loan option & 1.040 & 1.077 & 1.397 & 1.484 & -0.010 & 1.009 & 1.130 & 1.182 \\
\hline
\end{tabular}

increase the odds of purchasing insurance by nearly $100 \%$. These are not materially different across variants. Types of insurance reflect public versus private insurers. Farmers with the subjective variant are materially more in favor of public insurers than private insurers, particularly when measured by mixed Logit (objective $=1.895$ and subjective $=2.93$ ). The odds for the control variant are less than both subjective and objective for both conditional and mixed Logits. Likewise, farmers with the subjective variant are $35.7 \%$ and $40.7 \%$ more likely than those primed with the objective variant (under conditional and mixed Logits, respectively) to insure if the insurance can be used as loan collateral.

\subsection{Willingness to pay}

Our conclusion that our sample of farmers were more homogenous, than heterogenous, in their insurance preferences is clearer in the WTP estimates in Table 6. The WTP measures are obtained by dividing the estimated coefficients in Tables 3 and 4 by the negative of the coefficient of the premium attribute (see Eq. 8). The unit of measurement is RMB. It can be seen that the differences between the two models are trivial, and that the preponderance of homogeneity is preserved across variants.

The claim starting point is referenced in terms of minimum damage requirement for the crop insurance. This appears to be the most important attribute in crop insurance demand. An increase in 5\% (a decrease in coverage by 5\%) decreases the demand by 59.86 (or $11.97 \mathrm{RMB}$ for $1 \%$ ) for the objective variant and 55.42 for the subjective variant. In comparison, the control decreases by a substantially lower 31.11 (or 6.22 RMB for $1 \%$ ).

The subjective variant places more value on higher indemnity (WTP $=0.13 \mathrm{RMB}$ per $100 \mathrm{RMB}$ of indemnity) which is more than twice as much as the objective variant $(\mathrm{WTP}=0.06 \mathrm{RMB}$ per $100 \mathrm{RMB}$ of indemnity). The preferences of the control (WTP $=0.07 \mathrm{RMB}$ per $100 \mathrm{RMB}$ of indemnity) is similar to that of the objective variant and nearly half that of the subjective variant.

Likewise, we find that the subjective variant has a greater WTP (25.49 RMB) for public provision of crop insurance, which suggests that farmers place far more value on the implicit guarantee of payment that comes along with public vs private insurance. This attribute is still important for the objective variant (WTP $=12.78 \mathrm{RMB}$ ) and control (WTP $=13.62 \mathrm{RMB}$ ) but only by about half as much. 
Finally, the WTP for a linked-credit option is not significant for the objective variant and control but is substantial for the subjective variant (WTP $=12.15 \mathrm{RMB}$ ). In other words, farmers under the subjective variant would be willing to pay an additional 12.15 RMB for the option of linking the insurance to agricultural credit.

What can we conclude from these results? The first conclusion is that by priming farmers to anchor on future versus historical risks appears to matter. With the exception of the claim starting point the preferences of the objective variant is reasonably close to the preferences of the control. This suggests to us that members of the control group when considering insurance are more likely to consider historical risks, or at least strongly align these historical beliefs with their subjective beliefs. The subjective variant differs considerably in WTP from the control across all four WTP attributes and differs from the objective variant in all but the claim starting point.

\subsection{Heterogenous choice and the mixed Logit model}

In this last section, we discuss heterogenous choice across the three variants. As previously discussed the mixed Logit model aggregates the coefficients of individual Logit regression groupings. The standard deviations about the coefficients are reported in Table 4 and show significant heterogeneity across farmers. These standard deviations are equally, if not more, important than the mean coefficients. Assuming that the coefficients are normally distributed, Figs. 3, 4, 5, 6 and 7 illustrate the degree of heterogeneity by insurance attribute. Each figure includes three probability distributions for the objective, subjective and control variants. The distributions are demarked by the point $\beta_{j}=0$. In all instances, the distribution of $\beta_{j}$ spans this zero line, suggesting that some respondents consider the attributes with favor while others do not. The percentages above and below $\beta_{j}=0$ are identified in the upper grid for objective, subjective and control, respectively (Table 6).

The claim starting point depicted in Fig. 3 reveals that while the mean response to this attribute is negative, nearly $25.1 \%$ of objective variant, $34.3 \%$ of subjective variants, and $7.4 \%$ of control view decreasing coverage (increasing claim starting point favorably. In other words, while the majority of respondents prefer more coverage, a minority have a revealed preference for lower coverage levels. As can be visually observed the standard deviation about the control variant is strikingly lower than those primed for objective and subjective risks.

The crop premium attribute in Fig. 4 is likewise negative on average with more than $74 \%$ of farmers preferring lower premiums. The variance about the subjective variant is similar to the control, but the standard deviation for the objective variant has nearly twice the standard deviation (0.122). As with the insurance coverage attribute in Fig. 3, priming farmers to consider historical/objective risks triggers a greater degree of heterogeneity than the subjective prime and control.

In comparison, the distribution about the crop indemnity attribute in Fig. 5 is positive for the majority of farmers, and with a similar degree of heterogeneity. The mean value is higher for the objective variant and lowest for the subjective 


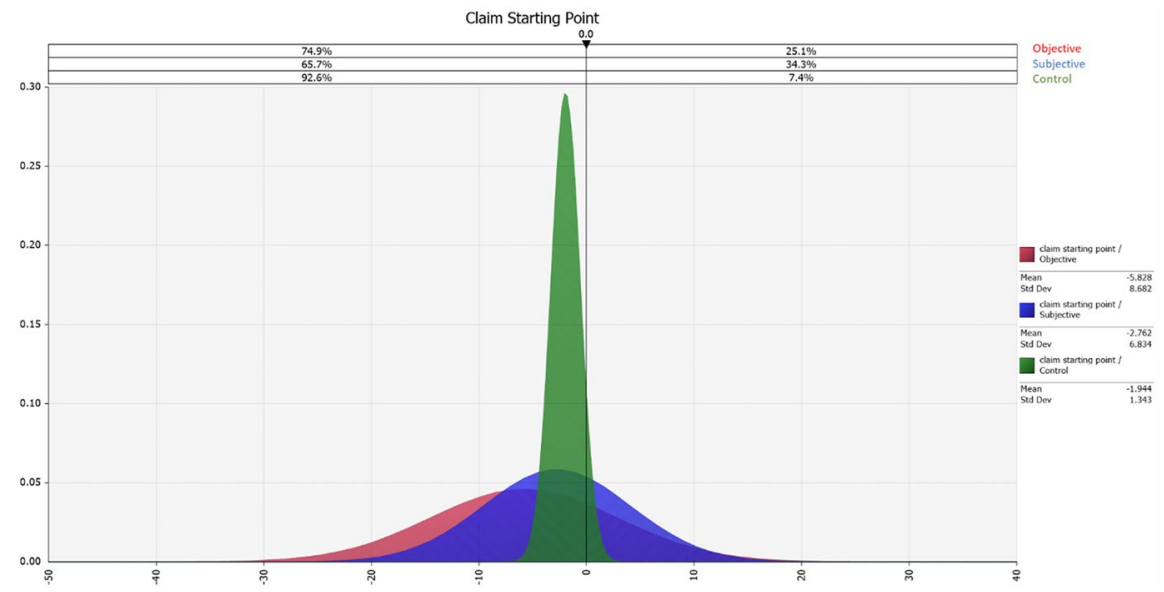

Fig. 3 Heterogenous choice in claim starting point from mixed Logit model

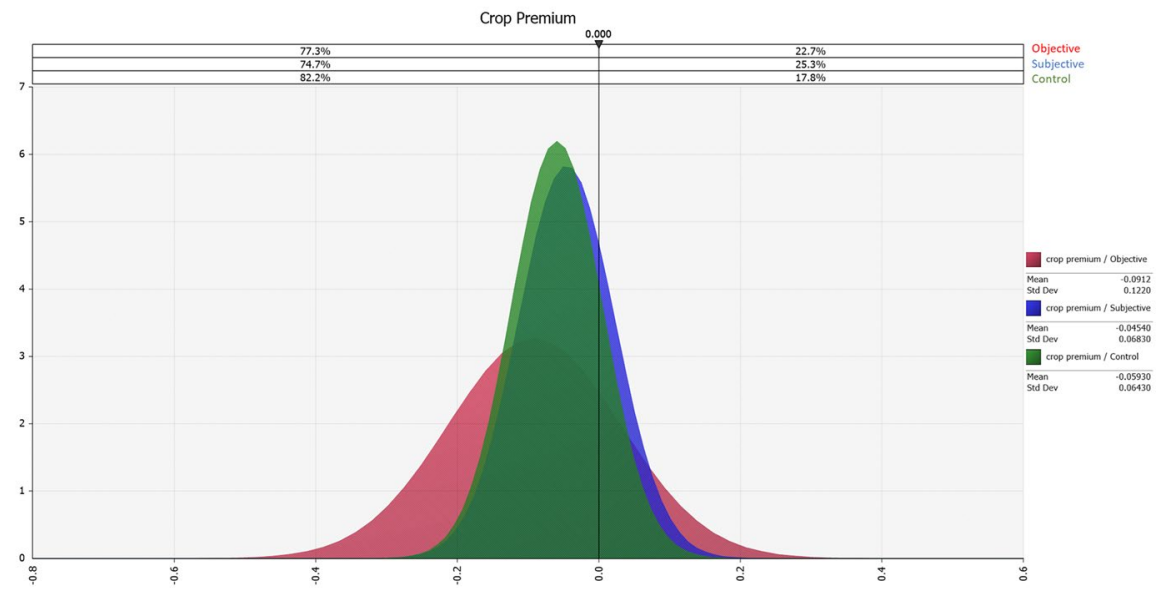

Fig. 4 Heterogenous choice in crop premium from mixed Logit model

variant with the higher majority of objective variant $(89.9 \%)$ having a positive response to higher indemnity.

Figure 6 captures heterogeneity in preference for insurance providers. The majority of respondents favor public provision of insurance (i.e., the government), while $32.5 \%$ of objective variants, $22.1 \%$ of subjective variants and $30.9 \%$ of control favor private providers.

Finally, Fig. 7 illustrates heterogeneity on the linked-credit attribute. Perhaps due to some overconfidence triggered by the subjective prime, farmers do not see the need to provide 'insurance' for credit. The control variant is centered on zero, 


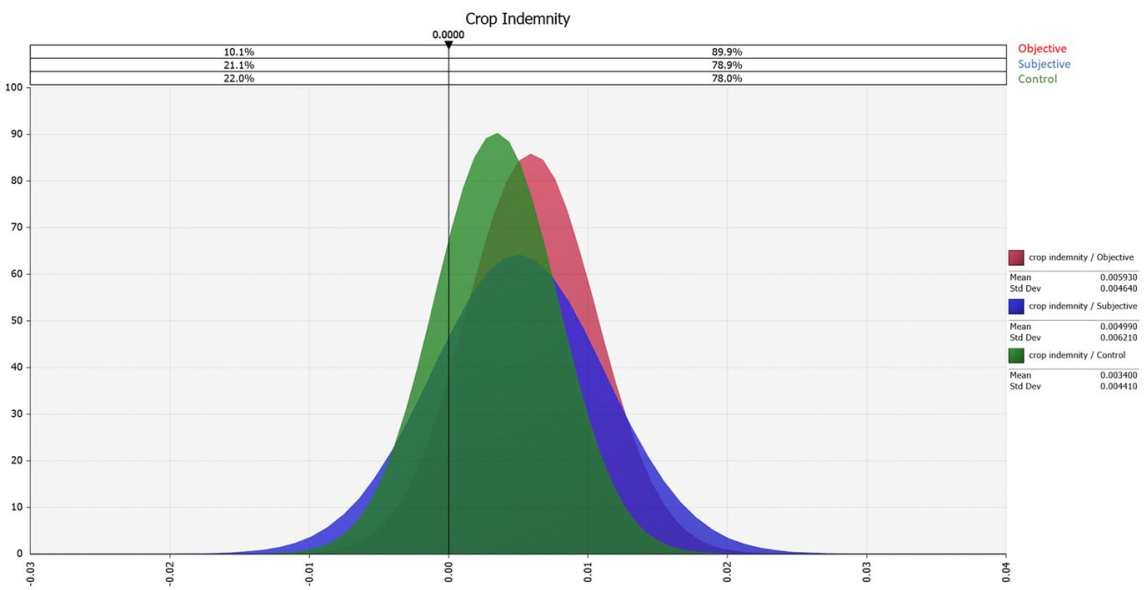

Fig. 5 Heterogenous choice in crop indemnity from mixed Logit model

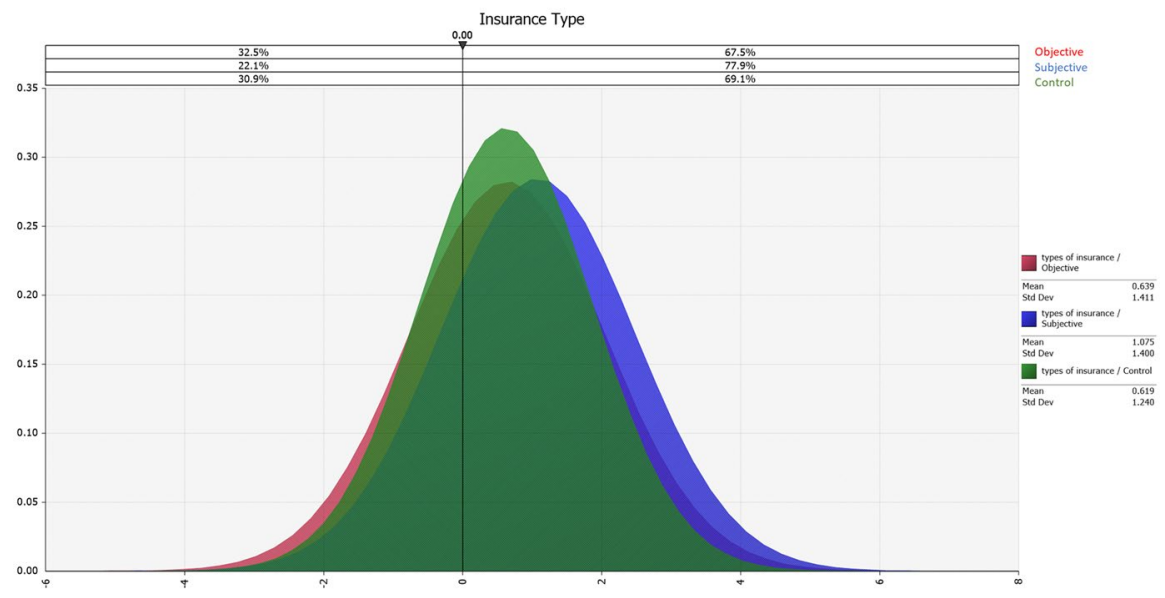

Fig. 6 Heterogenous choice in insurance type from mixed Logit model

but again we observe that farmers primed with the historical/objective variant show greater heterogeneity.

The representations of heterogeneity across farmers in Figs. 3, 4, 5, 6 and 7 support the proposition that how farmers view insurance depends upon framing. By design the three priming variants were randomly assigned so if there is no framing effect one would expect that the means and standard deviations across variants should be similar if not equal. This does not appear to be the case. The experiment shows that whether farmers are primed to consider past history results in a different cognitive response toward insurance than those who are primed to consider future probabilities. This also holds when compared to the control. 


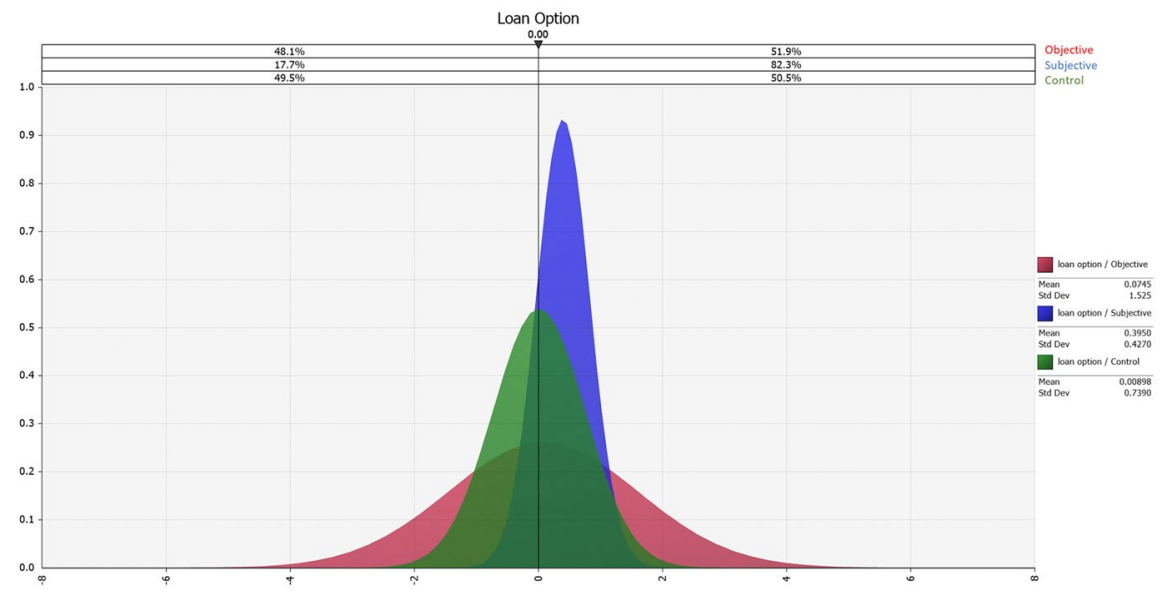

Fig. 7 Heterogenous choice in loan option from mixed Logit model

Table 6 Willingness to pay (WTP)

\begin{tabular}{|c|c|c|c|c|c|c|c|c|}
\hline & \multicolumn{2}{|c|}{ Objective } & \multicolumn{2}{|c|}{ Subjective } & \multicolumn{2}{|l|}{ Control } & \multicolumn{2}{|l|}{ Total } \\
\hline & $\mathrm{CL}$ & ML & CL & ML & CL & ML & CL & ML \\
\hline Claim starting point & -59.86 & -63.90 & -55.42 & -60.84 & -31.11 & -32.78 & -47.94 & -46.56 \\
\hline Crop indemnity & 0.06 & 0.07 & 0.13 & 0.11 & 0.07 & 0.06 & 0.08 & 0.07 \\
\hline Types of insurance & 12.78 & 7.01 & 25.49 & 23.68 & 13.62 & 10.44 & 16.34 & 14 \\
\hline Loan option & 0.79 & 0.82 & 12.15 & 8.70 & -0.26 & 0.15 & 3.19 & 10.16 \\
\hline
\end{tabular}

\section{Conclusions}

The central hypothesis of this paper is that farmers willingness to participate, or demand for crop insurance, differs as to whether their risk frame is based on objective (historical) or subjective (future) risks. We have shown farmers' willingness to pay for crop insurance given objective or subjective beliefs is in line with the heuristic affect (Loewenstein et al. 2001). Our experiment validates that priming farmers to anchor on future versus historical risks suggests that members of the control group when considering insurance are more likely to consider historical risks. The results highlight that farmers with objective beliefs are more sensitive to the claim starting point and crop premium, and less sensitive to indemnity, insurance types, and credit concerns. The subjective variant, similarly, differs considerably in WTP from the control across all four WTP attributes and differs from the objective variant.

Our results suggest a possible role of objective and subjective beliefs in China's crop insurance purchase decisions. From the marketing point of view, insurers should consider how farmers 'feel' about insurance. While farmers will likely 
consider future risks in terms of their decision, the actuarial structure of insurance will be based mainly on past risks. If subjective beliefs differ considerably from these objective actuarial measures, there may be resistance to purchasing insurance. But this is not a general result since for more than $50 \%$ of our cases, farmers subjective beliefs when measured in terms of probabilities, were less confident than their objective beliefs.

In terms of future research, there is a possibility that belief distributions create latent cognitive bias when choosing crop insurance. Farmers could make clear to distinguish between subjective beliefs and subjective probabilities, but latent subjective belief could potentially be elicited through the specification of a utility function (Andersen et al. 2014).

Funding This study was funded in part by a Government of China, Project 111 funding, administered by the Central University of Finance and Economics, Beijing PRC with advisors and Principal Investigators Ming Zhou and Ken Sen-Tan, and by W.I. Meyers Endowment Funds, Cornell University.

\section{Declarations}

Conflict of interest The authors declare that they have no conflict of interest.

Ethical approval This study went through, and was approved, by the human subjects Internal Review Board (IRB), Cornell University.

\section{References}

Andersen, S., J. Fountain, G.W. Harrison, and E.E. Rutström. 2014. Estimating subjective probabilities. Journal of Risk and Uncertainty 48 (3): 207-229.

Anhui Agricultural Insurance (Anhua). 2019a. Corn insurance terms. http://www.ahic.com.cn/u/cms/ anhua/201602/151417216cti.pdf.

Anhui Agricultural Insurance (Anhua). 2019b. Introduction on wheat insurance. http://www.ahic.com.cn/ plantingRisk/45394.jhtml.

Babcock, B.A. 2015. Using cumulative prospect theory to explain anomalous crop insurance coverage choice. American Journal of Agricultural Economics 97 (5): 1371-1384.

Bessler, D.A. 1980. Aggregated personalistic beliefs on yields of selected crops estimated using ARIMA processes. American Journal of Agricultural Economics 62: 666-674.

Buzby, J., P. Kenkel, J. Skees, J. Pease, and F. Benson. 1994. A comparison of subjective and historical yield distributions with implications for multiple peril crop insurance. Agricultural Finance Review 54 (1): 15-23.

Camerer, C., and D. Lovallo. 1999. Overconfidence and excess entry: An experimental approach. American Economic Review 89 (1): 306-318.

China Banking and Insurance Regulatory Commission. 2020. 2020 Annual Report. http://www.cbirc.

China Banking Regulatory Commission (CBRC). 2010. Opinions on strengthening the cooperation between agriculture-related credit and agriculture-related insurance. http://www.cbrc.gov.cn/govVi ew_BCADB5AC986744B69E8129E489968A3E.html.

Dalhaus, T., B.J. Barnett, and R. Finger. 2020. Behavioral weather insurance: Applying cumulative prospect theory to agricultural insurance design under narrow framing. PLOS ONE 15 (5): e0232267.

Eckles, D.L., and J.V. Wise. 2013. Loss aversion, probability weighting, and the demand for insurance. Terry College of Business Working Paper, University of Georgia. 
Fischhoff, B., P. Slovic, and S. Lichtenstein. 1977. Knowing with certainty: The appropriateness of extreme confidence. Journal of Experimental Psychology: Human Perception and Performance 3 (4): 552-564.

Fischhoff, B., P. Slovic, and S. Lichtenstein. 1978. Fault trees: Sensitivity of estimated failure probabilities to problem representation. Journal of Experimental Psychology: Human Perception and Performance 4: 342-355.

Gardner, B., and R. Kramer. 1986. Experience with crop insurance programs in the United States. In Crop insurance for agricultural development, ed. P. Hazell, C. Pomareda, and A. Valdes. Baltimore: The Johns Hopkins University Press.

Gervais, S., J.B. Heaton, and T. Odean. 2002. The positive role of overconfidence and optimism in investment policy. Working Paper, Wharton School, University of Pennsylvania.

Glauber, J. 2004. Crop insurance reconsidered. American Journal of Agricultural Economics 86 (5): 1179-1195.

Harrison, G.W., and J.M. Ng. 2018. Welfare effects of insurance contract non-performance. The Geneva Risk and Insurance Review 43 (1): 39-76.

Harrison, G.W. and J.T. Swarthout. 2019. Belief distribution, overconfidence, and baye's rule. Working Paper. Georgia State University.

Houston, D.B. 1964. Risk, insurance and sampling. Journal of Risk and Insurance 31 (4): 511-538.

Hsee, C.K., and H.C. Kunreuther. 2000. The affection effect in insurance decisions. Journal of Risk and Uncertainty 20: 141-159.

Hsee, C.K., and S. Menon. 1999. Affection effect in consumer choices. Unpublished data. University of Chicago.

Johnson, R., and B. Orme. 2003. Getting the most from CBC, Sawtooth Software Research Paper Series. Sawtooth Software, Sequim.

Johnson, E.J., J. Hershey, J. Meszaros, et al. 1993. Framing, probability distortions, and insurance decisions. Journal of Risk and Uncertainty 7: 35-51.

Kahneman, D., and A. Tversky. 1979. Prospect theory: An analysis of decision under risk. Econometrica 47: 263-291.

Knight, F.H. 1921. Risk, uncertainty and profit. Boston: Houghton Mifflin.

Kunreuther, H., and M.V. Pauly. 2018. Dynamic insurance decision-making for rare events: The role of emotions. The Geneva Papers on Risk and Insurance-Issues and Practice 43 (2): 335-355.

Kusev, P., P.V. Schaik, and S. Aldrovandi. 2012. Preferences induced by accessibility: Evidence from priming. Journal of Neuroscience Psychology and Economics 5: 250-258.

Lichtenstein, S., B. Fischhoff, and L.D. Phillips. 1982. Calibration of probabilities: The state of the art. Decision Making and Change in Human Affairs. https://doi.org/10.1007/978-94-010-1276-8_19.

Loewenstein, G., E. U. Weber, C. K. Hsee, and N. Welch. 2001. Risk as feelings. Psychological Bulletin 127 (2): 267-286.

McFadden, D. 1973. Conditional logit analysis of qualitative choice behavior: Chapter 4. In Frontiers in economics, ed. P. Zarambka, 105-142. New York: Academic Press.

McFadden, D. 2001. Economic choices. American Economic Review 91 (3): 351-378.

McFadden, D., and K. Train. 2000. Mixed MNL models for discrete response. Journal of Applied Econometrics 15 (5): 447-470.

McFadden, D., W.B. Tye, and K. Train. 1977. An application of diagnostic tests for the independence from irrelevant alternatives property of the multinomial logit model, 39-45. Berkeley: Institute of Transportation Studies, University of California.

Murphy, S.T., and R.B. Zajonc. 1993. Affect, cognition, and awareness: Affective priming with optimal and suboptimal stimulus exposures. Journal of Personality and Social Psychology 64 (5): 723-739.

Ndegwa, M.K., A. Shee, C.G. Turvey, and L. You. 2020. Uptake of insurance-embedded credit in presence of credit rationing: Evidence from a randomized controlled trial in Kenya. Agricultural Finance Review 80 (5): 745-766. https://doi.org/10.1108/AFR-10-2019-0116.

Orme, B. 1998. Sample size issues for conjoint analysis studies. Sawtooth Software Technical Paper, Sequim.

Pease, J., E. Wade, J. Skees, and M. Shrestha. 1993. Comparisons between subjective and statistical forecasts of crop yield. Review of Agricultural Economics 15 (2): 339-350.

Pfeffer, I. 1956. Insurance and economic theory. Homewood: Richard D. Irwin, Inc.

Ramirez, O.A., and C.A. Carpio. 2012. Premium estimation inaccuracy and the actuarial performance of the US crop insurance program. Agricultural Finance Review. 72 (1): 117-133. 
Rose, J.M., and M.C.J. Bliemer. 2013. Sample size requirements for stated choice experiments. Transportation 40: 1021-1041.

Shee, A., C.G. Turvey, and A. Marr. 2021. Heterogeneous demand and supply for an insurance-linked credit product in Kenya: A stated choice experiment approach. Journal of Agricultural Economics $72(1): 244-267$.

Sherrick, B.J. 2002. The accuracy of producers' probability beliefs: Evidence and implications for insurance valuation. Journal of Agricultural and Resource Economics 27 (1): 77-93.

Slovic, P., M.L. Finucane, P. Ellen, and D.G. MacGregor. 2002. The affect heuristic. In Heuristics and biases: The psychology of intuitive thought, ed. T. Gilovich, D. Griffin, and D. Kahneman, 397-420. Cambridge: Cambridge University Press.

Spinnewijn, J. 2012. Heterogeneity, demand for insurance and adverse selection. CEPR Discussion Paper No. DP8833. Available at SSRN: http://ssrn.com/abstract=2013824.

Svenson, O. 1981. Are we all less risky and more skillful than our fellow drivers? Acta Psychologica 47 (2): 143-148.

Train, K.E. 2009. Discrete choice methods with simulation. Cambridge: Cambridge University Press.

Turvey, C.G., X. Gao, R. Nie, L. Wang, and R. Kong. 2013. Subjective risks, objective risks and the crop insurance problem in rural China. The Geneva Papers on Risk and Insurance-Issues and Practice 38 (3): 612-633.

Turvey, C.G., and R. Kong. 2009. Business and financial risks of small farm households in China. China Agricultural Economic Review 1 (2): 155-172.

Tversky, A., and D. Kahneman. 1992. Advances in prospect theory: Cumulative representation of uncertainty. Journal of Risk and Uncertainty 5 (4): 297-323.

Umarov, A., and B.J. Sherrick. 2005. Farmers' subjective yield distributions: Calibration and implications for crop insurance valuation, Selected paper presented at the American Agricultural Economics Association (AAEA) Annual Meeting Providence, Rhode Island July: 24-27.

Wang, H.H., L. Liu, D.L. Ortega, Y. Jiang, and Q. Zheng. 2020. Are smallholder farmers willing to pay for different types of crop insurance? An application of labelled choice experiments to Chinese corn growers. The Geneva Papers on Risk and Insurance-Issues and Practice 45: 86-110.

Willett, A.H. 1951. The economic theory of risk and insurance. Philadelphia: University of Pennsylvania Press.

Zajonc, R.B. 1980. Feeling and thinking: Preferences need no inferences. American Psychologist 35 (2): $151-175$. 